\title{
Dyslipidemia Induced by Drugs Used for the Prevention and Treatment of Vascular Diseases
}

\author{
Konstantinos Tziomalos ${ }^{1}$, Vasilios G. Athyros $^{2}$, Asterios Karagiannis ${ }^{2}$ and Dimitri P. Mikhailidis ${ }^{1, *}$ \\ ${ }^{I}$ Department of Clinical Biochemistry (Vascular Prevention Clinic) and Department of Surgery, Royal Free Campus, \\ University College London Medical School, University College London (UCL), London, UK \\ ${ }^{2}$ Second Propedeutic Department of Internal Medicine, Aristotle University, Hippokration Hospital, Thessaloniki, Greece
}

\begin{abstract}
Dyslipidemia is a major vascular risk factor. Interestingly, several agents used for the prevention and treatment of vascular diseases have an adverse effect on the lipid profile. In addition, agents belonging to the same class (e.g. beta blockers) can have significantly different actions on lipid levels. We summarize the effects of drugs used for the prevention and treatment of vascular diseases on the lipid profile. These effects should be considered when selecting a specific agent, particularly in high-risk patients.
\end{abstract}

Keywords: Dyslipidemia, antihypertensive agents, antidiabetic agents, lipid-modifying agents, antiobesity agents.

\section{INTRODUCTION}

Elevated levels of low density lipoprotein cholesterol (LDL-C) are a major vascular risk factor [1]. Low levels of high density lipoprotein cholesterol (HDL-C) are also associated with higher vascular morbidity and mortality [1-3]. The relationship between triglyceride (TG) levels and vascular events is more controversial but elevated TG levels also appear to be associated with increased vascular risk [4]. Interestingly, several agents that are used for the prevention and treatment of vascular diseases have an adverse effect on the lipid profile (Table 1). The aim of the present review is to summarize the effects of these drugs on lipids.

\section{SEARCH METHODS}

A literature search (using PubMed) was performed using the following key words: "diuretics", "beta blockers", "calcium channel blockers", "angiotensin converting enzyme inhibitors", "angiotensin receptor blockers", "alpha blockers", "moxonidine", "minoxidil", "rosiglitazone", "pioglitazone", "metformin", "sulphonylureas", "insulin", "acarbose", "repaglinide", "nateglinide", "sitagliptin", "vildagliptin", "exenatide", "pramlintide", "orlistat", "sibutramine", "rimonabant", "bile acid sequestrants", "fibrates", "omega 3 fatty acids", "LDL-C", "HDL-C" and "triglycerides" up to 15 June 2009. The authors also manually reviewed the references of retrieved articles for any pertinent material.

\section{ANTIHYPERTENSIVE AGENTS}

Non-selective beta blockers (e.g. propranol) increase TG levels and lower HDL-C levels without affecting LDL-C

\footnotetext{
*Address correspondence to this author at the Department of Clinical Biochemistry, Royal Free Hospital Campus, University College London Medical School, University College London (UCL), Pond Street, London NW3 2QG, UK; Tel: +44 207830 2258; Fax: +44 207830 2235;

E-mail: MIKHAILIDIS@aol.com
}

levels $[5,6]$. In contrast, beta1-selective blockers (e.g. atenolol and metoprolol) do not appear to have an adverse effect on the lipid profile [5, 7-10] and in some studies increased HDL-C levels and lowered total cholesterol (TC) and TG levels [11]. However, atenolol increased TG levels in other studies [12, 13]. Both non-selective and beta1selective blockers may exacerbate preexisting hypertriglyceridemia and cases of pancreatitis have been reported in patients treated with these agents $[14,15]$. Beta1-selective blockers with intrinsic sympathomimetic activity (celiprolol, acebutolol and nebivolol) lowered LDL-C and TG levels and also increased HDL-C levels [5, 6]. Atenolol lowered HDL$\mathrm{C}$ levels and increased LDL-C and TG levels compared with celiprolol [16]. Nebivolol, a beta1-selective blocker which also stimulates nitric oxide release, does not appear to change lipid parameters significantly $[8,13]$. However, a fall in HDL-C levels during nebivolol treatment was reported in another study [17]. Carvedilol, a non-selective beta blocker with alpha1 selective blocking activity, appears to have more beneficial effects on the lipid profile than beta1-selective blockers [11, 18, 19]. Carvedilol did not change TC levels but lowered TG levels and increased HDL-C levels more than atenolol [11]. In another study, atenolol decreased HDL-C levels more than carvedilol [18]. Carvedilol also lowered TC levels more than metoprolol [19]. In addition, metoprolol increased TG levels whereas carvedilol had no significant effect [19]. Interestingly, several polymorphisms of the beta 2 and beta3 adrenoreceptor genes appear to be associated with increased risk for experiencing an increase in LDL-C and TG levels during treatment with beta blockers [20, 21].

Hydrochlorothiazide at a dose of 6.25-12.5 mg/day does not appear to adversely affect the lipid profile [22]. Hydrochlorothiazide $25 \mathrm{mg}$ /day did not change TC or HDL-C levels but increased TG levels $[12,23]$. A number of metaanalyses showed that hydrochlorothiazide at a dose $>25$ $\mathrm{mg} /$ day increases TC and TG levels more than lower doses 
Table 1. Adverse Lipid Effects of Agents Used for the Prevention and Treatment of Vascular Diseases

\begin{tabular}{|c|c|c|}
\hline Agent & Adverse Effect on The Lipid Profile & Reference \\
\hline Non-selective beta blockers & $\begin{array}{l}\uparrow \text { TG levels } \\
\downarrow \text { HDL-C levels }\end{array}$ & {$[5,6,14,15]$} \\
\hline Beta1-selective blockers & $\uparrow$ TG levels (no effect or $\downarrow$ in other studies) & {$[5,7-15]$} \\
\hline Nebivolol & $\downarrow$ HDL-C levels (no effect in other studies) & {$[8,13,15]$} \\
\hline Hydrochlorothiazide ( $\geq 25 \mathrm{mg} /$ day) & $\begin{array}{l}\uparrow \text { TG levels } \\
\uparrow \text { TC levels }\end{array}$ & {$[6,22]$} \\
\hline Chlorthalidone & $\uparrow$ LDL-C levels & [6] \\
\hline Indapamide & $\uparrow$ LDL-C levels (no effect in other studies) & {$[6,21,24]$} \\
\hline Pioglitazone & $\uparrow$ LDL-C levels & {$[46,47]$} \\
\hline Rosiglitazone & $\begin{array}{l}\uparrow \text { LDL-C levels } \\
\uparrow \text { TG levels }\end{array}$ & {$[46,47]$} \\
\hline Orlistat & $\downarrow$ HDL-C levels & {$[56]$} \\
\hline Bile-acid sequestrants & $\uparrow$ TG levels & {$[1,64-66]$} \\
\hline Fibrates & $\uparrow$ LDL-C levels (in patients with hypertriglyceridemia) & {$[1,67]$} \\
\hline Omega-3 fatty acids & $\uparrow$ LDL-C levels (in patients with severe hypertriglyceridemia) & {$[68-70]$} \\
\hline
\end{tabular}

TG = triglyceride; HDL-C = high density lipoprotein cholesterol; TC = total cholesterol; LDL-C = low density lipoprotein cholesterol.

$[6,24]$. In addition, thiazide diuretics lowered HDL-C levels only in diabetic patients [6]. Interestingly, the increase in LDL-C and TG levels with thiazide diuretics appears to be more pronounced in men [6]. In addition, the rise in LDL-C levels appears to be greater in patients with higher baseline LDL-C levels [6]. Chlorthalidone increased LDL-C levels more than other thiazide diuretics [6]. The non-thiazide diuretic indapamide at a dose of $2.5 \mathrm{mg} /$ day or at $1.5 \mathrm{mg} /$ day in a sustained release form reduced blood pressure to an extent similar or greater than hydrochlorothiazide $25 \mathrm{mg} /$ day [23, 25]. Indapamide in these doses did not change TC, TG or HDL-C levels [23, 26]. However, in a meta-analysis indapamide did not change TG levels but increased LDL-C levels [6]. In comparative studies, indapamide $2.5 \mathrm{mg} /$ day and hydrochlorothiazide $12.5 \mathrm{mg} /$ day had a similar effect on lipid profile [27]. However, indapamide $2.5 \mathrm{mg} /$ day increased TG levels more than hydrochlorothiazide $25 \mathrm{mg} / \mathrm{day}$ [23].

Calcium channel blockers appear to have neutral effects on the lipid profile [6, 28-31]. An increase in HDL-C levels was also reported in some studies $[12,32]$.

Angiotensin converting enzyme inhibitors increased HDL-C levels and lowered TC and TG levels in some reports $[12,30,33]$. In others, they did not affect the lipid profile [7, 34] or lowered only LDL-C [35] or TG levels [6]. Angiotensin II receptor blockers increased HDL-C levels and lowered LDL-C and TG levels [28, 36-39]. In other studies they did not affect the lipid profile [35] or lowered only LDL-C levels [40].

Some large randomized controlled trials compared the effects of different classes of antihypertensive agents on the lipid profile. In the Losartan Intervention For Endpoint re- duction in hypertension (LIFE) study, HDL-C levels decreased less with losartan-based treatment than with atenolol-based treatment [41]. In the Antihypertensive and Lipid-Lowering Treatment to Prevent Heart Attack Trial (ALLHAT), TC levels decreased more with amlodipine- and lisinopril-based treatment than with chlorthalidonebased treatment [42]. However, it is difficult to compare the effects of antihypertensive agents on lipids in randomized controlled trials since most patients in these studies are treated with multiple classes of antihypertensive agents.

Doxazosin, an alpha1-blocker, increased HDL-C levels and lowered LDL-C and TG levels [6, 33, 43]. Other alpha blockers have similar beneficial effects on the lipid profile [6]. The less frequently used antihypertensive agents moxonidine and minoxidil appear to lower LDL-C levels without affecting TG or HDL-C levels [44, 45].

\section{ANTIDIABETIC AGENTS}

Both rosiglitazone and pioglitazone increased LDL-C levels [46, 47]. However, it appears that pioglitazone lowers small dense LDL particles (which are potentially more atherogenic) whereas rosiglitazone has a smaller or no effect on LDL size [48-50]. In addition, rosiglitazone increased TG levels whereas pioglitazone decreased TG levels [46]. Both these thiazolidinediones increased HDL-C levels [46, 51]. In comparative studies, pioglitazone induced a greater reduction in TG levels, a larger increase in HDL-C levels, a smaller increase in TC and LDL-C levels as well as a greater shift towards larger, more buoyant LDL particles [48-50]. Other antidiabetic agents appear to have neutral or beneficial effects on the lipid profile. Metformin decreased TG and LDL-C levels and did not affect HDL-C levels [46]. Sulphonylureas, acarbose and glinides (repaglinide and nateg- 
linide) decreased TG levels and did not affect LDL-C or HDL-C levels [46]. The "newer" oral antidiabetic drugs sitagliptin and vildagliptin (which inhibit dipeptidyl peptidase IV) appear to have a neutral effect on the lipid profile [52]. Preliminary data suggest that vildagliptin improves postprandial lipemia [53]. Insulin appears to reduce TG and increase HDL-C levels, particularly in patients with poor glycemic control [54]. "Newer" antidiabetic agents administered by subcutaneous injection include exenatide (a glucagon-like peptide 1 agonist) and pramlintide (an amylin analogue) [54]. Neither exenatide nor pramlintide appear to alter the lipid profile significantly $[52,55]$.

\section{ANTIOBESITY AGENTS}

Orlistat not only reduces body weight but also lowers LDL-C levels [56]. However, a small but significant decrease in HDL-C levels was reported during orlistat treatment [56]. Orlistat does not appear to alter TG levels significantly [56]. Sibutramine, another agent approved for the management of obesity, decreases TG levels and increases HDL-C concentration [56]. Sibutramine does not significantly affect LDL-C levels [56]. Rimonabant, an antiobesity agent that was withdrawn for safety reasons, increased HDL$\mathrm{C}$ levels and reduced TG levels [57-63].

\section{LIPID PROFILE-MODIFYING AGENTS}

Bile-acid sequestrants (resins) decrease LDL-C levels but also increase TG levels [1]. Colesevelam, a newer resin which appears to be better tolerated than older members of this class, also increased TG levels [64-66]. Accordingly, resin monotherapy is contraindicated in patients with TG levels $>400 \mathrm{mg} / \mathrm{dl}(4.5 \mathrm{mmol} / \mathrm{l})$ and should be avoided when TG levels are $>200 \mathrm{mg} / \mathrm{dl}(2.2 \mathrm{mmol} / \mathrm{l})$ [1].

In patients with hypercholesterolemia, fibrates lower LDL-C levels by $10-20 \%$ [1, 67]. However, an increase in LDL-C levels might be observed when fibrates are given to patients with hypertriglyceridaemia [1,67]. This appears to be due to an increase in very low density lipoprotein (VLDL) lipolysis by lipoprotein lipase [67].

Omega-3 fatty acids lower TG levels but increase LDL-C levels, particularly in patients with severe hypertriglyceridemia [68-70]. This increase in LDL-C levels appears to be due to a shift to larger, more buoyant and (potentially) less atherogenic LDL particles [68, 71, 72]. Interestingly, in patients with hypertriglyceridemia who were treated with statins, adding omega-3 fatty acids did not affect LDL-C levels [73]. In addition, omega-3 fatty acids lowered LDL-C levels in patients with normal TG levels $[68,70]$.

\section{CONCLUSIONS}

Several drugs used for the prevention and treatment of vascular diseases appear to have an adverse effect on the lipid profile. Moreover, agents belonging to the same class (e.g. beta-blockers) can have significantly different actions on lipid levels. These effects might have to be considered when selecting a specific agent, particularly in high-risk patients. However, it is unclear whether the adverse lipid effects of these agents reduce their protective effect against vascular events. In addition, the effect on lipids is a surrogate endpoint. Therefore, only large randomized clinical trials with vascular endpoints should guide our therapeutic decisions.

\section{LIST OF ABBREVIATIONS}

$\begin{array}{ll}\text { HDL-C } & \text { High density lipoprotein cholesterol } \\ \text { LDL-C } & \text { Low density lipoprotein cholesterol } \\ \text { LIFE } & =\begin{array}{l}\text { Losartan Intervention For Endpoint reduction } \\ \text { in hypertension }\end{array} \\ \mathrm{TC} & =\text { Total cholesterol } \\ \mathrm{TG} & =\text { Triglyceride } \\ \text { VLDL } & =\text { Very low density lipoprotein }\end{array}$

\section{DECLARATION OF INTEREST}

This review was written independently; no company or institution supported it financially. Some of the authors have attended conferences, given lectures and participated in advisory boards or trials sponsored by various pharmaceutical companies. Konstantinos Tziomalos is supported by a grant from the Hellenic Atherosclerosis Society.

\section{REFERENCES}

[1] Third Report of the National Cholesterol Education Program (NCEP) Expert Panel on Detection, Evaluation, and Treatment of High Blood Cholesterol in Adults (Adult Treatment Panel III) final report. Circulation 2002; 106: 3143-421.

[2] Barter P, Gotto AM, LaRosa JC, et al. HDL cholesterol, very low levels of LDL cholesterol, and cardiovascular events. N Engl J Med 2007; 357: 1301-10.

[3] deGoma EM, Leeper NJ, Heidenreich PA. Clinical significance of high-density lipoprotein cholesterol in patients with low lowdensity lipoprotein cholesterol. J Am Coll Cardiol 2008; 51: 49-55.

[4] Sarwar N, Danesh J, Eiriksdottir G, et al. Triglycerides and the risk of coronary heart disease: 10, 158 incident cases among 262, 525 participants in 29 Western prospective studies. Circulation 2007; 115: 450-8.

[5] Fogari R, Zoppi A, Corradi L, Preti P, Mugellini A, Lusardi P. Beta-blocker effects on plasma lipids during prolonged treatment of hypertensive patients with hypercholesterolemia. J Cardiovasc Pharmacol 1999; 33: 534-9.

[6] Kasiske BL, Ma JZ, Kalil RS, Louis TA. Effects of antihypertensive therapy on serum lipids. Ann Intern Med 1995; 122: 133-41.

[7] Lakshman MR, Reda DJ, Materson BJ, Cushman WC, Freis ED. Diuretics and beta-blockers do not have adverse effects at 1 year on plasma lipid and lipoprotein profiles in men with hypertension. Department of Veterans Affairs Cooperative Study Group on Antihypertensive Agents. Arch Intern Med 1999; 159: 551-8.

[8] Fogari R, Zoppi A, Lazzari P, et al. Comparative effects of nebivolol and atenolol on blood pressure and insulin sensitivity in hypertensive subjects with type II diabetes. J Hum Hypertens 1997; 11 : 753-7.

[9] Fagerberg B, Berglund A, Holme E, Wilhelmsen L, Elmfeldt D. Metabolic effects of controlled-release metoprolol in hypertensive men with impaired or diabetic glucose tolerance: a comparison with atenolol. J Intern Med 1990; 227: 37-43.

[10] Karagiannis A, Mikhailidis DP, Kakafika AI, Tziomalos K, Athyros VG. Atenolol: differences in mode of action compared with other antihypertensives. An opportunity to identify features that influence outcome? Curr Pharm Des 2007; 13: 229-39.

[11] Giugliano D, Acampora R, Marfella R, et al. Metabolic and cardiovascular effects of carvedilol and atenolol in non-insulin-dependent diabetes mellitus and hypertension. A randomized, controlled trial. Ann Intern Med 1997; 126: 955-9.

[12] Nandeesha H, Pavithran P, Madanmohan T. Effect of antihypertensive therapy on serum lipids in newly diagnosed essential hypertensive men. Angiology 2009; 60: 217-20.

[13] Rizos E, Bairaktari E, Kostoula A, et al. The combination of nebivolol plus pravastatin is associated with a more beneficial meta- 
bolic profile compared to that of atenolol plus pravastatin in hypertensive patients with dyslipidemia: a pilot study. J Cardiovasc Pharmacol Ther 2003; 8: 127-34.

[14] Durrington PN, Cairns SA. Acute-pancreatitis: a complication of beta-blockade. Br Med J (Clin Res Ed) 1982; 284: 1016.

[15] O'Donoghue DJ. Acute pancreatitis due to nadolol-induced hypertriglyceridaemia. Br J Clin Pract 1989; 43: 74-5.

[16] Howes LG, Lykos D, Rennie GC. Effects of antihypertensive drugs on coronary artery disease risk: a meta-analysis. Clin Exp Pharmacol Physiol 1996; 23: 555-8.

[17] Pesant Y, Marc-Aurele J, Bielmann P, et al. Metabolic and antihypertensive effects of nebivolol and atenolol in normometabolic patients with mild-to-moderate hypertension. Am J Ther 1999; 6: 137-47.

[18] Uzunlulu M, Oguz A, Yorulmaz E. The effect of carvedilol on metabolic parameters in patients with metabolic syndrome. Int Heart J 2006; 47: 421-30.

[19] Bakris GL, Fonseca V, Katholi RE, et al. Metabolic effects of carvedilol vs metoprolol in patients with type 2 diabetes mellitus and hypertension: a randomized controlled trial. JAMA 2004; 292 : 2227-36.

[20] Iaccarino G, Trimarco V, Lanni F, et al. beta-Blockade and increased dyslipidemia in patients bearing Glu27 variant of beta2 adrenergic receptor gene. Pharmacogenomics J 2005; 5: 292-7.

[21] Isaza C, Henao J, Ramirez E, Cuesta F, Cacabelos R. Polymorphic variants of the beta2-adrenergic receptor (ADRB2) gene and ADRB2-related propanolol-induced dyslipidemia in the Colombian population. Methods Find Exp Clin Pharmacol 2005; 27 : 237-44

[22] Neutel JM. Metabolic manifestations of low-dose diuretics. Am J Med 1996; 101: 71S-82S.

[23] Spence JD, Huff M, Barnett PA. Effects of indapamide versus hydrochlorothiazide on plasma lipids and lipoproteins in hypertensive patients: a direct comparison. Can J Clin Pharmacol 2000; 7: 32-7.

[24] Ames RP. A comparison of blood lipid and blood pressure responses during the treatment of systemic hypertension with indapamide and with thiazides. Am J Cardiol 1996; 77: 12b-6b.

[25] Emeriau JP, Knauf H, Pujadas JO, et al. A comparison of indapamide SR $1.5 \mathrm{mg}$ with both amlodipine $5 \mathrm{mg}$ and hydrochlorothiazide $25 \mathrm{mg}$ in elderly hypertensive patients: a randomized doubleblind controlled study. J Hypertens 2001; 19: 343-50.

[26] Weidmann P. Metabolic profile of indapamide sustained-release in patients with hypertension: data from three randomised doubleblind studies. Drug Saf 2001; 24: 1155-65.

[27] Krum H, Skiba M, Gilbert RE. Comparative metabolic effects of hydrochlorothiazide and indapamide in hypertensive diabetic patients receiving ACE inhibitor therapy. Diabet Med 2003; 20: 708-12.

[28] Derosa G, Cicero AF, Bertone G, et al. Comparison of the effects of telmisartan and nifedipine gastrointestinal therapeutic system on blood pressure control, glucose metabolism, and the lipid profile in patients with type 2 diabetes mellitus and mild hypertension: a 12month, randomized, double-blind study. Clin Ther 2004; 26: 122836.

[29] Bakris GL, Smith AC, Richardson DJ, et al. Impact of an ACE inhibitor and calcium antagonist on microalbuminuria and lipid subfractions in type 2 diabetes: a randomised, multi-centre pilot study. J Hum Hypertens 2002; 16: 185-91.

[30] Masuo K, Mikami H, Ogihara T, Tuck ML. Metabolic effects of long-term treatments with nifedipine-retard and captopril in young hypertensive patients. Am J Hypertens 1997; 10: 600-10.

[31] Spirou A, Rizos E, Liberopoulos EN, et al. Effect of barnidipine on blood pressure and serum metabolic parameters in patients with essential hypertension: a pilot study. J Cardiovasc Pharmacol Ther 2006; 11: 256-61.

[32] Reuter MK, Lorenz H, Verho P, Smith N, Degen A, Verho M. Effects of felodipine ER, a dihydropyridine calcium antagonist, on blood pressure and serum lipids. Curr Med Res Opin 1998; 14: 97103 .

[33] Grimm RH Jr, Flack JM, Grandits GA, et al. Long-term effects on plasma lipids of diet and drugs to treat hypertension. Treatment of Mild Hypertension Study (TOMHS) Research Group. JAMA 1996; 275: 1549-56.

[34] Oksa A, Gajdos M, Fedelesova V, Spustova V, Dzurik R. Effects of angiotensin-converting enzyme inhibitors on glucose and lipid metabolism in essential hypertension. J Cardiovasc Pharmacol 1994; 23: 79-86.

[35] Derosa G, Cicero AF, Ciccarelli L, Fogari R. A randomized, double-blind, controlled, parallel-group comparison of perindopril and candesartan in hypertensive patients with type 2 diabetes mellitus. Clin Ther 2003; 25: 2006-21.

[36] Inoue $\mathrm{T}$, Morooka $\mathrm{T}$, Moroe $\mathrm{K}$, Ikeda $\mathrm{H}$, Node $\mathrm{K}$. Effect of telmisartan on cholesterol levels in patients with hypertension Saga Telmisartan Aggressive Research (STAR). Horm Metab Res 2007; 39: 372-6.

[37] Derosa G, Fogari E, D'Angelo A, et al. Metabolic effects of telmisartan and irbesartan in type 2 diabetic patients with metabolic syndrome treated with rosiglitazone. J Clin Pharm Ther 2007; 32: 261-8.

[38] Kyvelou SM, Vyssoulis GP, Karpanou EA, et al. Effects of antihypertensive treatment with angiotensin II receptor blockers on lipid profile: an open multi-drug comparison trial. Hellenic J Cardiol 2006; 47: 21-8.

[39] Papadakis JA, Mikhailidis DP, Vrentzos GE, Kalikaki A, Kazakou I, Ganotakis ES. Effect of antihypertensive treatment on plasma fibrinogen and serum HDL levels in patients with essential hypertension. Clin Appl Thromb Hemost 2005; 11: 139-46.

[40] Hanefeld M, Abletshauser C. Effect of the angiotensin II receptor antagonist valsartan on lipid profile and glucose metabolism in patients with hypertension. J Int Med Res 2001; 29: 270-9.

[41] Olsen MH, Wachtell K, Beevers G, et al. Effects of losartan compared with atenolol on lipids in patients with hypertension and left ventricular hypertrophy: the Losartan Intervention For Endpoint reduction in hypertension study. J Hypertens 2009; 27: 567-74.

[42] Major outcomes in high-risk hypertensive patients randomized to angiotensin-converting enzyme inhibitor or calcium channel blocker vs diuretic: The Antihypertensive and Lipid-Lowering Treatment to Prevent Heart Attack Trial (ALLHAT) JAMA 2002; 288: 2981-97.

[43] Pessina AC, Ciccariello L, Perrone F, et al. Clinical efficacy and tolerability of alpha-blocker doxazosin as add-on therapy in patients with hypertension and impaired glucose metabolism. Nutr Metab Cardiovasc Dis 2006; 16: 137-47.

[44] Lumb PJ, McMahon Z, Chik G, Wierzbicki AS. Effect of moxonidine on lipid subfractions in patients with hypertension. Int J Clin Pract 2004; 58: 465-8.

[45] Johnson BF, Errichetti A, Urbach D, Hoch K, Johnson J. The effect of once-daily minoxidil on blood pressure and plasma lipids. J Clin Pharmacol 1986; 26: 534-8.

[46] Bolen S, Feldman L, Vassy J, et al. Systematic review: comparative effectiveness and safety of oral medications for type 2 diabetes mellitus. Ann Intern Med 2007; 147: 386-99.

[47] Rizos CV, Elisaf MS, Mikhailidis DP, Liberopoulos EN. How safe is the use of thiazolidinediones in clinical practice? Expert Opin Drug Saf 2009; 8: 15-32

[48] Berneis K, Rizzo M, Stettler C, et al. Comparative effects of rosiglitazone and pioglitazone on fasting and postprandial lowdensity lipoprotein size and subclasses in patients with Type 2 diabetes. Expert Opin Pharmacother 2008; 9: 343-9.

[49] Deeg MA, Buse JB, Goldberg RB, et al. Pioglitazone and rosiglitazone have different effects on serum lipoprotein particle concentrations and sizes in patients with type 2 diabetes and dyslipidemia. Diabetes Care 2007; 30: 2458-64.

[50] Rizzo M, Christ ER, Rini GB, Spinas GA, Berneis K. The differential effects of thiazolidindiones on atherogenic dyslipidemia in type 2 diabetes: what is the clinical significance? Expert Opin Pharmacother 2008; 9: 2295-303.

[51] Home PD, Pocock SJ, Beck-Nielsen H, et al. Rosiglitazone evaluated for cardiovascular outcomes in oral agent combination therapy for type 2 diabetes (RECORD): a multicentre, randomised, openlabel trial. Lancet 2009; 373: 2125-35.

[52] Amori RE, Lau J, Pittas AG. Efficacy and safety of incretin therapy in type 2 diabetes: systematic review and meta-analysis. JAMA 2007; 298: 194-206.

[53] Matikainen N, Manttari S, Schweizer A, et al. Vildagliptin therapy reduces postprandial intestinal triglyceride-rich lipoprotein particles in patients with type 2 diabetes. Diabetologia 2006; 49: 204957 .

[54] Nathan DM, Buse JB, Davidson MB, et al. Medical management of hyperglycemia in type 2 diabetes: a consensus algorithm for the ini- 
tiation and adjustment of therapy: a consensus statement of the American Diabetes Association and the European Association for the Study of Diabetes. Diabetes Care 2009; 32: 193-203.

[55] Hoogwerf BJ, Doshi KB, Diab D. Pramlintide, the synthetic analogue of amylin: physiology, pathophysiology, and effects on glycemic control, body weight, and selected biomarkers of vascular risk. Vasc Health Risk Manag 2008; 4: 355-62.

[56] Rucker D, Padwal R, Li SK, Curioni C, Lau DC. Long term pharmacotherapy for obesity and overweight: updated meta-analysis. BMJ 2007; 335: 1194-9.

[57] Despres JP, Golay A, Sjostrom L. Effects of rimonabant on metabolic risk factors in overweight patients with dyslipidemia. $\mathrm{N}$ Engl J Med 2005; 353: 2121-34.

[58] Despres JP, Ross R, Boka G, Almeras N, Lemieux I. Effect of rimonabant on the high-triglyceride/ low-HDL-cholesterol dyslipidemia, intraabdominal adiposity, and liver fat: the ADAGIO-Lipids trial. Arterioscler Thromb Vasc Biol 2009; 29: 416-23.

[59] Pi-Sunyer FX, Aronne LJ, Heshmati HM, Devin J, Rosenstock J. Effect of rimonabant, a cannabinoid-1 receptor blocker, on weight and cardiometabolic risk factors in overweight or obese patients: RIO-North America: a randomized controlled trial. JAMA 2006; 295: 761-75.

[60] Scheen AJ, Finer N, Hollander P, Jensen MD, Van Gaal LF. Efficacy and tolerability of rimonabant in overweight or obese patients with type 2 diabetes: a randomised controlled study. Lancet 2006; 368: 1660-72.

[61] Van Gaal L, Pi-Sunyer X, Despres JP, McCarthy C, Scheen A. Efficacy and safety of rimonabant for improvement of multiple cardiometabolic risk factors in overweight/obese patients: pooled 1-year data from the Rimonabant in Obesity (RIO) program. Diabetes Care 2008; 31 Supp1 2: S229-40.

[62] Van Gaal LF, Rissanen AM, Scheen AJ, Ziegler O, Rossner S. Effects of the cannabinoid-1 receptor blocker rimonabant on weight reduction and cardiovascular risk factors in overweight patients: 1year experience from the RIO-Europe study. Lancet 2005; 365 : 1389-97.

[63] Van Gaal LF, Scheen AJ, Rissanen AM, et al. Long-term effect of $\mathrm{CB} 1$ blockade with rimonabant on cardiometabolic risk factors: two year results from the RIO-Europe Study. Eur Heart J 2008; 29: 1761-71.

[64] Tziomalos K, Athyros VG, Mikhailidis DP. Colesevelam improves glycemic control and lipid management in inadequately controlled type 2 diabetes mellitus. Nat Clin Pract Endocrinol Metab 2009; 5: 16-7.

[65] Goldberg RB, Fonseca VA, Truitt KE, Jones MR. Efficacy and safety of colesevelam in patients with type 2 diabetes mellitus and inadequate glycemic control receiving insulin-based therapy. Arch Intern Med 2008; 168: 1531-40.

[66] Fonseca VA, Rosenstock J, Wang AC, Truitt KE, Jones MR. Colesevelam $\mathrm{HCl}$ improves glycemic control and reduces LDL cholesterol in patients with inadequately controlled type 2 diabetes on sulfonylurea-based therapy. Diabetes Care 2008; 31: 1479-84.

[67] Backes JM, Gibson CA, Ruisinger JF, Moriarty PM. Fibrates: what have we learned in the past 40 years? Pharmacotherapy 2007; 27: 412-24.

[68] Tziomalos K, Athyros VG, Karagiannis A, Mikhailidis DP. Omega-3 fatty acids: how can they be used in secondary prevention? Curr Atheroscler Rep 2008; 10: 510-7.

[69] Bays H. Clinical overview of Omacor: a concentrated formulation of omega-3 polyunsaturated fatty acids. Am J Cardiol 2006; 98 : 71i-6i.

[70] Robinson JG, Stone NJ. Antiatherosclerotic and antithrombotic effects of omega-3 fatty acids. Am J Cardiol 2006; 98: 39i-49i.

[71] Kelley DS, Siegel D, Vemuri M, Mackey BE. Docosahexaenoic acid supplementation improves fasting and postprandial lipid profiles in hypertriglyceridemic men. Am J Clin Nutr 2007; 86: 32433.

[72] Satoh N, Shimatsu A, Kotani K, et al. Purified eicosapentaenoic acid reduces small dense LDL, remnant lipoprotein particles, and C-reactive protein in metabolic syndrome. Diabetes Care 2007; 30: 144-6.

[73] Durrington PN, Bhatnagar D, Mackness MI, et al. An omega-3 polyunsaturated fatty acid concentrate administered for one year decreased triglycerides in simvastatin treated patients with coronary heart disease and persisting hypertriglyceridaemia. Heart 2001; 85: 544-8 